\title{
Alpha-lipoic acid enhances short-term spatial memory of mice in open-space forced swim-induced depression mouse model
}

Yusuf Yusha'u ${ }^{1 *}$, Umar Muhammad Adam ${ }^{1}$, Alhassan Abdul Wahab ${ }^{1}$, Malajiya Ibrahim Alhaji Saleh ${ }^{1}$ and Jamilu Ya'u ${ }^{2}$

${ }^{1}$ Department of Human Physiology, Faculty of Basic Medical Sciences, College of Medical Sciences, Ahmadu Bello University, Zaria-Nigeria. P.O. Box 2555, Zaria, Kaduna State, Nigeria.

${ }^{2}$ Department of Pharmacology and Therapeutics, Faculty of Pharmaceutical Sciences, Ahmadu Bello University, Zaria-Nigeria.

* Correspondence: yusufshau@gmail.com; Tel.: +2348100872166

Received: 29 May 2021; Accepted: 28 August 2021; Published: 26 September 2021

Edited by: Cheah Pike See (Universiti Putra Malaysia, Malaysia)

Reviewed by: Zurina Hassan (Universiti Sains Malaysia, Malaysia); Narison Kitiyanant (Mahidol University, Thailand) https://doi.org/10.31117/neuroscirn.v4i3.75

\begin{abstract}
Depression affects over 264 million people of all ages globally. Major depressive disorder significantly and chronically reduced quality of life by its association with functional impairment both at home and in the workplace. Depressive patients consistently complain about cognitive disturbances, significantly exacerbating the burden of this illness. Several studies have shown that alpha-lipoic acid (ALA) possesses mitochondrial, antioxidant, anti-inflammatory and anti-diabetic properties, indicating a basis for evaluating the efficacy of ALA in depression. Hence, this research aimed to assess the possible anti-depressant effect of ALA in mice exposed to the open space forced swim test (OSFST) model of depression. Twenty-five (25) Swiss albino mice were grouped into five groups $(n=5)$. Group 1: [Normal saline (NS)], Groups 2, 3 and 4 received graded doses of ALA 100, 200 and $400 \mathrm{mg} / \mathrm{kg}$, respectively, Group 5 received fluoxetine $20 \mathrm{mg} / \mathrm{kg}$ orally. The animals were subjected to OSFST, novel object recognition test (NORT) and Y-maze test. Serotonin, brainderived neurotrophic factor (BDNF), superoxide dismutase (SOD), malondialdehyde (MDA) and catalase levels of the mice were assessed. Treatment with ALA and fluoxetine significantly decreased immobility time compared to NS group in OSFST ( $p<0.05$ ). Also, ALA at doses of $200 \& 400 \mathrm{mg} / \mathrm{kg}$ and fluoxetine $20 \mathrm{mg} / \mathrm{kg}$ significantly increased spontaneous alternation ratio in the $Y$-maze test compared to the normal saline group $(p<0.05)$, however, no significant difference was observed in novel object recognition using NORT between NS, ALA and fluoxetine treated groups. Similarly, the level of serotonin, SOD and catalase were not altered between the ALA and fluoxetine treated groups and NS group. In contrast, fluoxetine $20 \mathrm{mg} / \mathrm{kg}$ increased the brain BDNF level of the mice $(p<0.05)$. Alpha-lipoic acid ameliorated depression in the OSFST murine model of depression and improved their cognition. Thus, ALA can be a promising candidate in the development of novel anti-depressant medication.
\end{abstract}

Keywords: Alpha-lipoic acid; fluoxetine; depression; open-space forced swim test; spatial short-term memory; immobility time;

C2021 by Yusha'u et al. for use and distribution according to the Creative Commons Attribution (CC BY-NC 4.0) license (https://creativecommons.org/licenses/by-nc/4.0/), which permits unrestricted non-commercial use, distribution, and reproduction in any medium, provided the original author and source are credited. 


\subsection{INTRODUCTION}

Depression has become a serious public health concern, as over 264 million people are affected globally (WHO, 2021). According to the World Health Organization, depression is the $4^{\text {th }}$ leading cause of disability globally and projects to be the first by 2030 (WHO, 2017). Depression is a psychological condition and may decrease work performance, interpersonal relationships, financial status, and the appearance of suicide ideation. Consequently, it may implicate physical well-being and increased morbidity and mortality (Brown et al., 2011). Furthermore, cognitive disturbances have been observed in MDD patients (Darcet et al., 2016). Impairment in short-term memory has been associated with depressive symptoms (Schweizer et al., 2018). A possible mechanism linking depression with the cognitive deficit is a decrease in BDNF observed in depressive patients based on the neuroplasticity hypothesis of depression (Liu et al., 2017a; Serafini, 2012).

In adult subjects with MDD, long-term therapy with certain anti-depressants may also link to cognitive side effects. For instance, long-term treatment with selective serotonin reuptake inhibitors has been linked to cognitive impairments, including difficulty in wordfinding, forgetfulness and mental slowing in MDD patients causing full or partial remission (Bortolato et al., 2016; Wroolie et al., 2006). There is a significant therapeutic time lag of weeks to months using currently available anti-depressants. Treatment-resistant depression is a public health challenge prompting research to identify new therapeutic strategies (Hashimoto, 2019; Matveychuk et al., 2020; Paula et al., 2020; Zemdegs et al., 2018). Similarly, in young adults, the suicidal risk may increase with agitation while using some anti-depressants (Baldessarini et al., 2020; WHO, 2021).

Several oxidative disturbances in depression have been reported in clinical and preclinical studies, including elevated lipid peroxidation levels, the decreasing activity of glutathione (GSH), catalase (CAT), and superoxide dismutase (SOD) and consequently, may contribute to the dysfunction of serotonergic and noradrenergic systems (Marcia et al., 2016). Similarly, it has been suggested that depression is an inflammatory disease of the central nervous system (CNS) and might be mediated via oxidative stress (Calheiros et al., 2013; Paula et al., 2020). In some depressive patients, antioxidants such as ascorbic acid, tocopherols, and coenzyme Q (CoQ) have shown promising, but without consensus on their efficacy (Paula et al., 2020).

Alpha-lipoic acid (ALA), or 1,2-dithiolane-3-pentanoic acid, is a naturally occurring dithiol compound synthesized enzymatically in the mitochondrion from octanoic acid (Katerii et al., 2019). In addition, ALA is absorbed from the diet and can cross the blood-brain barrier (Choi et al., 2015). ALA is a cofactor found in several multienzyme complexes (Karaarslan et al., 2013). ALA and its reduced form, dihydrolipoic acid (DHLA) are antioxidants in vivo (Dong et al., 2017; Mendoza-núñez et al., 2019; Triggiani, 2020). Several experimental models have shown that ALA exerts antioxidant effect via scavenging of reactive oxygen species (ROS). Therefore, ALA can effectively inhibit pathologies in which ROS have been implicated, such as diabetic neuropathy, ischemia-reperfusion injury, radiation injury and diabetes-induced oral implant failure (Dong et al., 2017; Karaarslan et al., 2013). In addition, ALA exerts its potent antioxidant effect by inducing endogenous antioxidants such as vitamin $E$ and glutathione (Kurumazuka et al., 2019).

Despite many approaches available to treat depression, only about $35 \%$ of depressed patients achieve remission upon receiving treatment with anti-depressants, and treatment response rates appear to reduce with each subsequent retry (Hashimoto, 2019; Paula et al., 2020). Hence, the quest for better therapeutic options. Due mainly to its antioxidant properties, ALA has been reported to protect against oxidative injury in various disease processes, including neurodegenerative disorders (Calheiros et al., 2013; Cekici \& Bakırhan, 2018; Silva et al., 2015; Uchida et al., 2015). In addition, several studies have shown the potential effect of ALA in improving insulin sensitivity (Liu et al., 2017b; Okanović et al., 2015; Salehi et al., 2019; Volchegorskiŭ et al., 2011). Since insulin resistance and impaired insulin signalling have been found to play an important role in the pathogenesis of MDD, comorbid metabolic disturbances aggravate the burden of depressive illness, including sharing pathophysiological pathways and common risk factors (Stuart \& Baune, 2012). In addition, insulin inhibits the reuptake of norepinephrine by pre-synaptic neurons serves and also enhance serotonin synthesis (Spielman et al., 2014). Alterations in insulin signalling are associated with mitochondrial dysfunction and cause the activation of pro-inflammatory pathways and increased oxidative stress and glutamate excitotoxicity, leading to 
neuroinflammation and neurodegeneration (Spielman et al., 2014). It is assumed that supplementation with ALA might result in anti-depressant effects in MDD patients via an elevation in insulin sensitivity and subsequent upregulation of monoamines (Salazar, 2000). Interestingly, preclinical studies and investigations in individuals affected by Alzheimer's disease provided evidence that ALA may enhance cognition via genetic mechanisms, including mitochondrial activity, antioxidant and antiinflammatory properties indicating a basis for evaluating ALA's efficacy in depression as well (Bortolato et al., 2016). Therefore, this study aimed to assess the possible anti-depressant effect of ALA in mice subjected to OSFST.

\subsection{MATERIALS AND METHODS}

\subsection{Experimental Design and Animal Treatment}

Twenty-five (25) healthy Swiss albino mice of both sexes weighing between 20-28 g with ages 6-8 weeks were obtained from the Department of Human Physiology, Ahmadu Bello University, Zaria and allowed access to feed and water ad libitum in a normal photoperiod. The animals were grouped into five groups, with five mice each $(n=5)$. Daily administration was carried out based on daily body weight per mouse an hour before the commencement of the experiment for 2 weeks via the oral route. Group I received normal saline $(10 \mathrm{ml} / \mathrm{kg})$, Groups II, III and IV received graded doses of ALA 100, 200 and $400 \mathrm{mg} / \mathrm{kg}$, respectively, while Group V received fluoxetine $20 \mathrm{mg} / \mathrm{kg}$. Ethical clearance was obtained from Ahmadu Bello University Committee on Animal Use and Care with ABUCAUC/2017/003.

\subsection{Drugs and Reagents}

Fluoxetine was purchased from Bristol Laboratories Ltd., Hertfordshire, UK, with Batch Number: 8775 and product license number: PL11311/0047. Alpha-lipoic acid was purchased from Puritan's Pride Inc. Ronkonkoma, NY 11779 the United States of America with a Product Code: B68499 02C 14-18988PPS and LOT \# T18B045-01 CC1. Mouse serotonin, BDNF, SOD, catalase and MDA ELISA Kits were purchased from Shanghai Coon Koon Biotech Co., Ltd. Shanghai, China with LOT \# 201907.

\subsubsection{Preparation of alpha-lipoic acid}

ALA $0.4 \mathrm{~g}$ was dissolved in $10 \mathrm{ml}$ of normal saline with the aid of 2 drops of tween-80 to form a stock concentration of $40 \mathrm{mg} / \mathrm{ml}$ and a dose of $400 \mathrm{mg} / \mathrm{kg}$. A serial dilution was carried out to form $200 \mathrm{mg} / \mathrm{kg}$ and $100 \mathrm{mg} / \mathrm{kg}$ doses.

\subsection{Behavioral Studies}

\subsubsection{Open-space forced swim test}

This protocol describes a simplified method for inducing a chronic depression-like state in mice as previously described (Stone \& Lin, 2011). Plastic tubs with dimensions $(24 \times 43 \times 23 \mathrm{~cm})$ were filled with tap water at $32-34{ }^{\circ} \mathrm{C}$ to a depth of $13 \mathrm{~cm}$. As shown in Figure 1, the open-space forced swim test (OSFST) was divided into habituation and testing phases. On day 1 of the habituation phase, the individual mouse was placed gently in the water tub and allowed to swim for $15 \mathrm{~min}$. After the swim, each mouse was approached slowly, captured through its tail with the index and third fingers and placed in its home cage. The temperature of the water tub was maintained $\left(32-34^{\circ} \mathrm{C}\right)$ at $30 \mathrm{~min}$ intervals by replacing $2 \mathrm{~L}$ with $2 \mathrm{~L}$ of hot water $\left(45-52^{\circ} \mathrm{C}\right)$ to maintain the temperature at $32-35^{\circ} \mathrm{C}$. Water in the tubs were changed entirely after eight trials. The swimming procedure was repeated for two additional days consecutively. On the fourth day of the habituation, the swim procedure was repeated, and the immobility time was recorded and used to match the animals into control and experimental groups.

Testing phase: Daily oral administration with NS, ALA and fluoxetine was instituted at $24 \mathrm{~h}$ after the day 4 swimming of the habituation phase and lasted for two weeks. Immobility time was recorded during the test session for 15 minutes at 1, 4, 7, 10 and 14 days of the testing phase (Figure 1). Immobility was recorded using a digital video camera. Immobility is defined as the absence of any limb or body movements, except those caused by respiration to keep the animal's nose above the water level.

\subsubsection{Y-maze test}

Y-maze apparatus was used to assess short-term spatial memory. A Y-maze apparatus has three arms that cross each other with $120^{\circ}$ between them with the dimensions: two equal arms $(15 \mathrm{~cm}$ length $x 7 \mathrm{~cm}$ width $x 12 \mathrm{~cm}$ height $)$ and one more extended arm $(20 \mathrm{~cm}$ length $\times 7 \mathrm{~cm}$ width $\times 12 \mathrm{~cm}$ height). In phase 1 , mice were placed into the apparatus at the start arm. Each mouse could have access to two arms, while the entrance to the third arm was blocked. In phase 2, the block in arm three was removed, the mouse was placed into the start arm and then allowed to access all three arms of the maze (Wolf et al., 2016). After each session, 
$70 \%$ ethanol was used to clean the apparatus to prevent any olfactory cues. Mice are expected to explore the new arm in phase 2 more frequently than a recently explored one. A lower frequency of exploration of the last previously explored arm is an indicator of better memory performance. The exploration frequency of 3 consecutive arms (A, B, and C) was considered an actual alternation. The percentage of alternation was calculated as follows: (actual alternation/maximal alternation -2$) \times 100$. Also, all numbers of entries were recorded (Yau et al., 2007).

\subsubsection{Novel object recognition test}

Novel object recognition test (NORT) apparatus is a rectangular arena that was made up of opaque plastic and measured $42 \mathrm{~cm} \times 52 \mathrm{~cm}$. The walls are $40 \mathrm{~cm}$ high. Mice were placed in the arena for 5 minutes, where they encountered two identical sample objects (sample phase). At the end of the sample phase, mice were placed back in their home cages for 5 minutes delay ( \pm 15 seconds).

For the testing phase, animals were returned to the arena for 3 minutes, where one of the familiar objects was replaced with a novel object. $70 \%$ ethanol was used to clean the arena and all objects between each session. Successful novel object recognition was indexed by greater exploration of the novel compared to the familiar object. The discrimination ratio was calculated as the total time spent exploring the recently seen object (novel object) divided by the time exploring both objects sampled at test (familiar objects) (Thur et al., 2014).

\section{Open-Space Forced Swim Test (OSFST)}

\section{HABITUATION PHASE (4 days)}

Day 1-3

Daily 15 minutes swimming: Immobility time not recorded
Day 4

15 minutes swimming: Immobility time recorded to match the animals into control and treatment groups

\section{TEST PHASE (14 days)}

Drug administered daily to test animals

Animals swam for 15 minutes, 1 hour after drug administration

Animals swam at days 1, 4, 7, 10 and 14 during which immobility time was recorded

Figure 1: Schedule for open-space forced swim test. 


\subsection{Brain Tissues Collection}

Collection and preparation of the mice brain tissues were done according to the method described by (Habila et al., 2012; Zatta et al., 2002). The mice were euthanized by decapitation under anaesthesia. A pair of scissors was inserted anteriorly to the olfactory bulb and opened to rupture the skull into two parts. Then, the brain tissue was immediately removed using a brain spatula and placed on an inverted Petri dish on ice. The forebrain was dissected, weighed and homogenized in $10 \mathrm{ml}$ of a medium containing a solution of $0.1 \mathrm{M}$ sodium phosphate $10 \mathrm{~W} / \mathrm{V}, \mathrm{pH} 7.5$. The total homogenate was centrifuged at $78 \times g$ for 7 minutes. Aliquots of resulting brain homogenates were stored at $-20^{\circ} \mathrm{C}$ until utilization. The supernatants were used for the determination of BDNF and serotonin levels.

\subsection{Collection of Blood Samples}

Mice blood samples were drawn by cardiac puncture and collected in plain tubes. The serum

was used for the determination of catalase, SOD and MDA activities.

\subsection{Determination of Brain Serotonin and BDNF Levels} Mouse serotonin assay kit CK-bio-16918 and mouse BDNF assay kit CK-bio-15795 (Shanghai, Coon Koon Biotechnology) ELISA, China were used to detect serotonin and BDNF concentrations, respectively, according to the manufacturer's protocol. Standards, control, and samples were pipetted into the 48-well plates pre-coated with objective antibody and streptavidin-Horse Radish Peroxide (HRP) wells, and any BDNF and serotonin present was bound by the immobilized antibodies, respectively. Enzyme-linked polyclonal antibodies specific for mouse BDNF and serotonin were added to the wells respectively after washing away any unbound substances. A substrate solution was added to the wells following a wash to remove any unbound antibody-enzyme reagent. When the stop solution was added, the enzyme reaction yielded a blue product that turned yellow. The intensity of the colour measured was in proportion to the amount of BDNF or serotonin bound in the initial step. The sample values were then read off from the standard curve for the corresponding concentrations of BDNF in $\mathrm{pg} / \mathrm{ml}$ and serotonin in $\mathrm{ng} / \mathrm{ml}$, respectively.

\subsection{Determination of Biomarkers of Oxidative Stress} Biomarkers of oxidative stress (CAT, SOD and MDA) activities were detected using ELISA kits (mouse CAT CKbio-15864, SOD CK-bio-16990, and MDA CK-bio-20387 respectively) Shanghai, Coon Koon Biotechnology, China. Serum collected from experimental animals and standard (provided in the kit) were dispensed into the 48-well plate pre-coated with objective antibody and streptavidin-HRP. CAT, SOD or MDA present was bound by the immobilized antibody in their respective wells. Enzyme-linked polyclonal antibodies specific for mouse CAT, SOD and MDA were added to the respective wells after washing away any unbound substances. A substrate solution was put in the wells after removing the unbound antibody-enzyme reagents. Then, when the stop solution was added, a blue product formed by the enzymatic reaction turned yellow. The amount of SOD, CAT or MDA bound in the initial step was in proportion to the intensity of the colour measured. The sample values were then read from the standard curve for the corresponding levels of CAT and SOD in U/ml and MDA in $\mathrm{pg} / \mathrm{ml}$, respectively.

\subsection{Statistical Analysis}

Results were expressed as Mean \pm SEM. All analyses were done using one-way analysis of variance (ANOVA), except data from open-space forced swim test and time spent on familiar and novel objects in NORT. Independent samples t-test was used to analyze the data for time spent on familiar and novel objects of NORT, while data for OSFST were analyzed by 2-way repeated-measures ANOVA followed by Tukey's posthoc test for multiple comparisons using SPSS version 23 and GraphPad prism version 8.0.2. for windows, respectively. Values with $p<0.05$ were considered statistically significant.

\subsection{RESULTS}

\subsection{Behavioral Studies}

\subsubsection{Depression studies}

Effects of alpha-lipoic acid on depression in mice exposed to open-space forced swim test (OSFST)

Two-way repeated measure ANOVA was conducted to access the effects of treatments and time on immobility time as a depression index. There were no statistically significant effects of time on the different treatment groups $[\mathrm{F}(3.319,66.39)=1.307, p>0.05]$, as expected no interaction was found between the treatments and time $[F(16,80)=0.7959, p>0.05]$. However, we found significant effects of treatment between the groups $[\mathrm{F}$ $(4,20)=9.949, p<0.005$. At day 7 the immobility time is decreased in ALA $100 \mathrm{mg} / \mathrm{kg}$, and fluoxetine group when compared with untreated normal saline group. At day 10 and 14 all the treatment groups had less immobility time when compared with the normal saline 


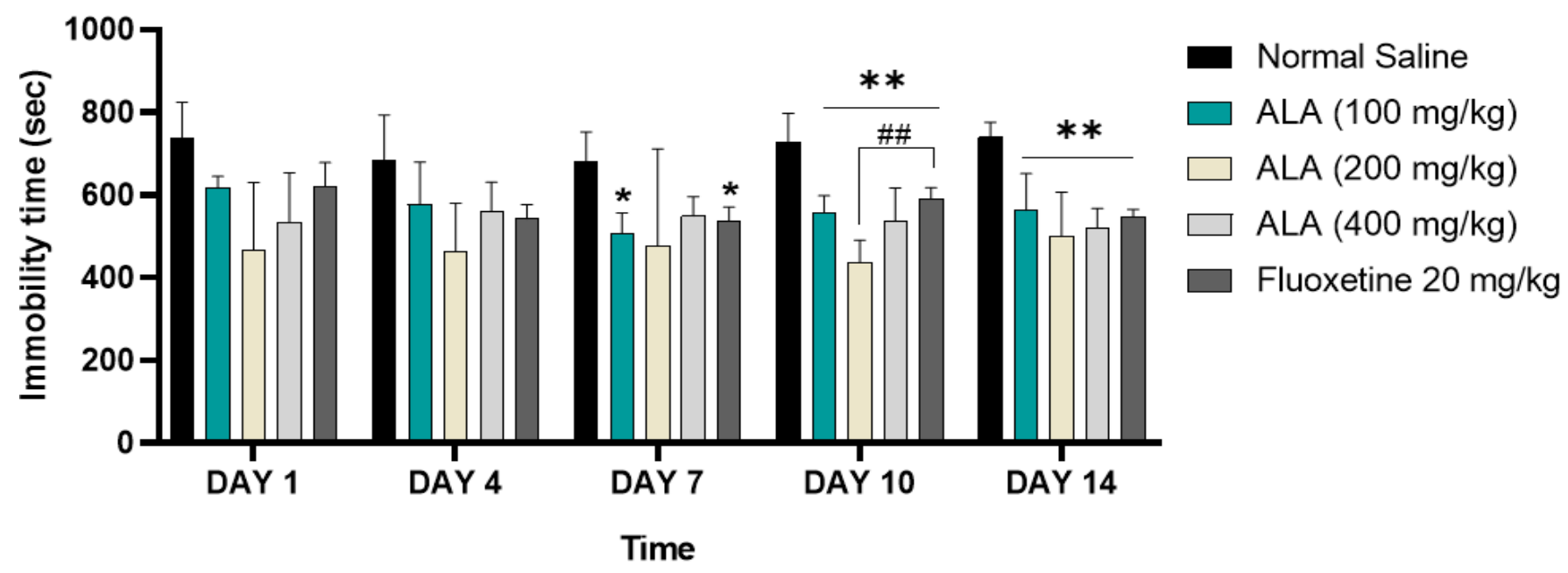

Figure 2: Effects of alpha-lipoic acid (ALA) on depression in mice exposed to open-space forced swim test. Results expressed as mean \pm SEM. ${ }^{*}, * *$ Mean difference is statistically significant when compared to the normal saline group at $p<0.05, p<0.005$, respectively, "\#mean difference statistically significant when compared with fluoxetine at $p<0.05$ ( $n=5)$, GraphPad Prism Version 8. ALA: Alpha-Lipoic Acid.

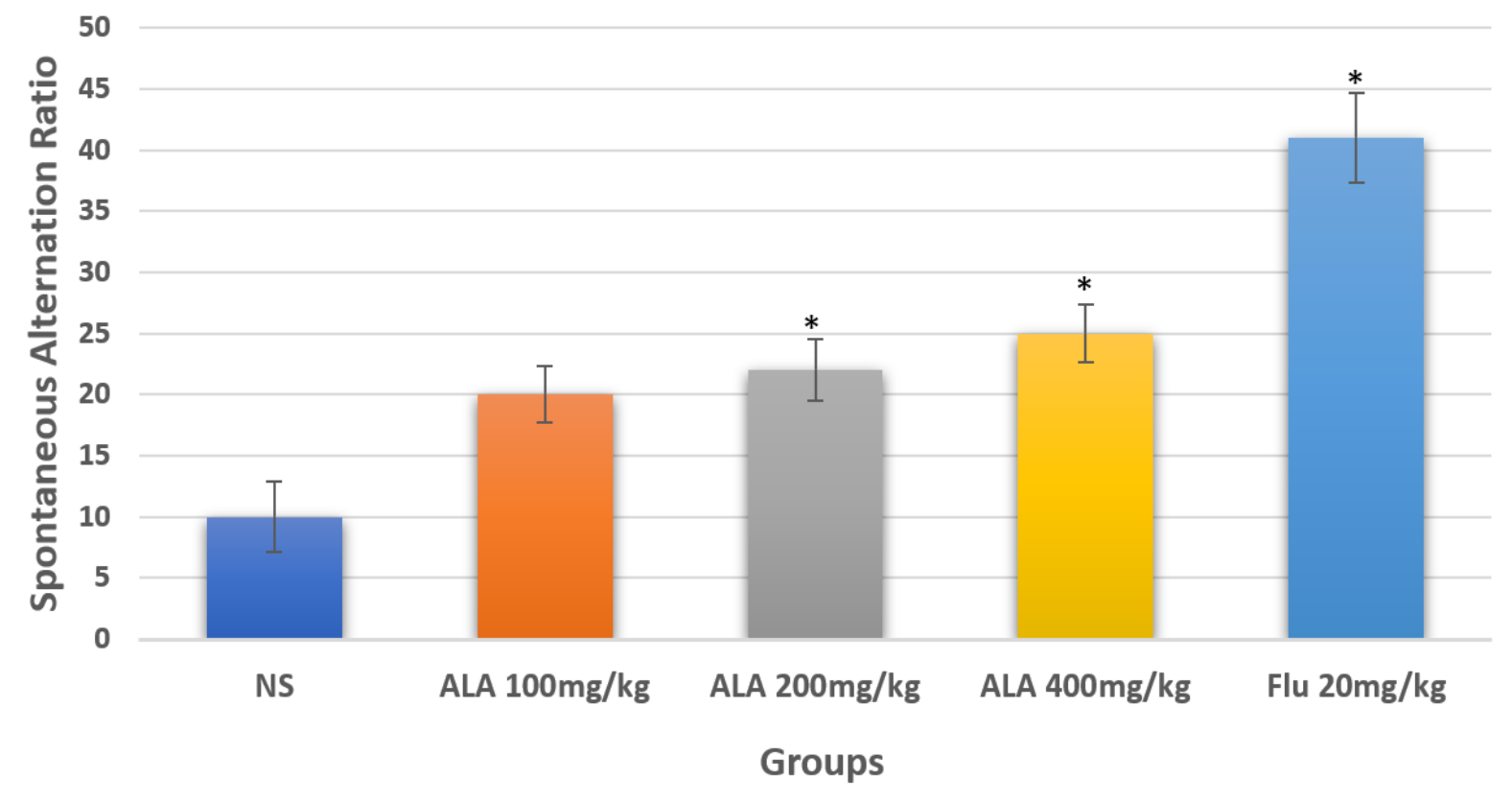

Figure 3: Spontaneous alternation of Y-maze test in OSFST-induced depressed mice. OSFST-induced depressed mice ( $n=5$ ) per group were treated with graded doses of ALA (100-400 mg/kg), Flu $(20 \mathrm{mg} / \mathrm{kg})$ and NS (10 ml/kg) for $14 \mathrm{days}$, and thereafter, spatial short-term memory was assessed using Y-maze test. ALA administration improved spatial short-term memory in OFST-induced depressed mice $(p<0.05)$. Data were represented as mean \pm SEM. * Statistically significant compared with the normal saline group at $p<0.05$. OSFST: Open Space Forced Swim Test, ALA: Alpha-Lipoic Acid, Flu: Fluoxetine, NS: Normal Saline 


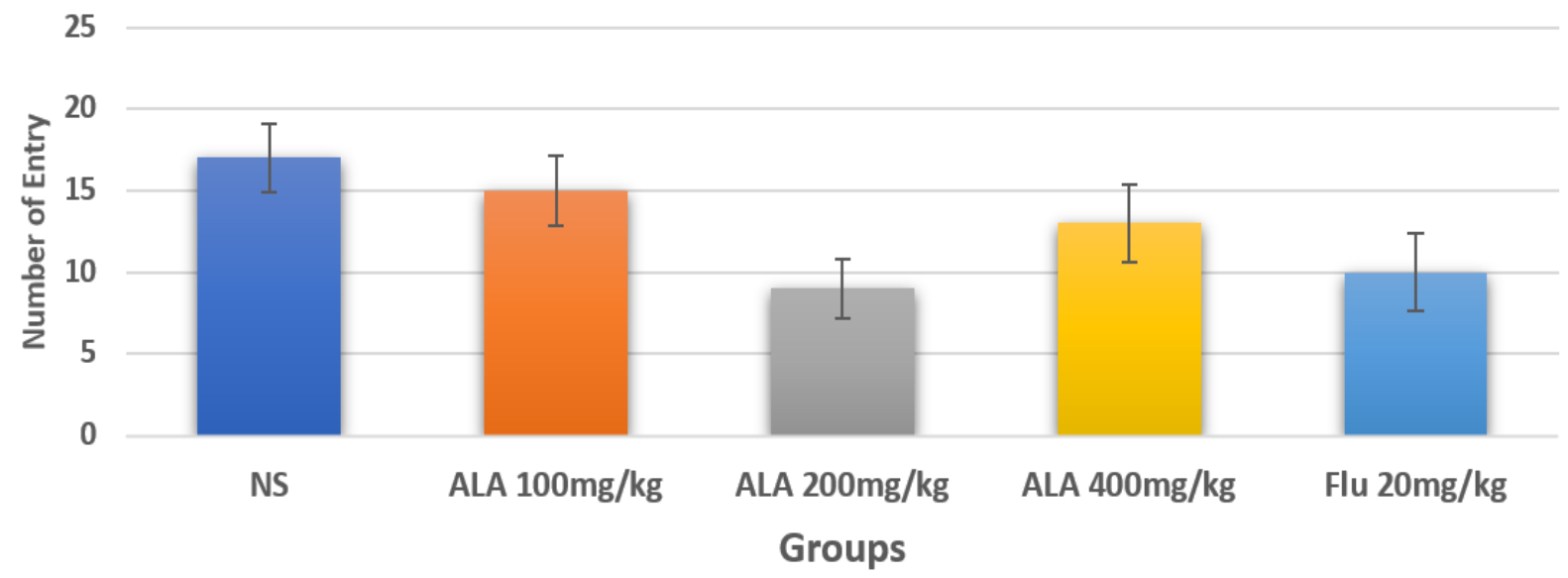

Figure 4: Number of entries into the arms in Y-maze test of OSFST-induced depressed mice. OSFST-induced depressed mice $(n=5)$ per group were treated with graded doses of ALA (100-400 mg/kg), Flu $(20 \mathrm{mg} / \mathrm{kg})$ and NS $(10 \mathrm{ml} / \mathrm{kg})$ for $14 \mathrm{days}$, and thereafter, spatial short-term memory was assessed using Y-maze test. ALA administration improves spatial short-term memory in OFST-induced depressed mice. Data were represented as mean \pm SEM. OSFST: Open-Space Forced Swim Test, ALA: Alpha-Lipoic Acid, Flu: Fluoxetine, NS: Normal Saline

group. We also observed a significant difference in the immobility time between ALA $200 \mathrm{mg} / \mathrm{kg}$ and fluoxetine (standard anti-depressant) group on day 10. Overall, the sub-chronic administration of different doses of ALA in depressed mice model decreases their depressive symptoms as assessed using immobility time (Figure 2).

\subsubsection{Memory tests}

\section{Effects of alpha-lipoic acid (ALA) on short-term} memory of open-space forced swim-induced depressed mice using Y-maze test

As shown in Figure 3, ALA (200 and $400 \mathrm{mg} / \mathrm{kg}$ ) and fluoxetine $(20 \mathrm{mg} / \mathrm{kg})$ treated groups had increased $(p<$ $0.05)$ spontaneous alternation ratio compared to the normal saline group. As shown in Figure 4, no statistically significant difference $(p>0.05)$ was observed in the number of entries into the arms of the $Y$-maze apparatus between the treatment groups and the normal saline group.

\section{Effects of alpha-lipoic acid on non-spatial short-term} memory using novel object recognition task in mice subjected to open-space forced swim test

As shown in Figure 5, the result of the discrimination ratio of the novel object recognition task showed no statistically significant difference $(p>0.05)$ between the treatment groups and the normal saline group. However, ALA 100 and $400 \mathrm{mg} / \mathrm{kg}$ significantly $(p<0.05)$ spent more time exploring the novel object as shown in Table 1.

\subsection{Biochemical Tests}

3.2.1 Effects of alpha-lipoic acid administration on brain serotonin level in mice subjected to open-space forced swim test

Figure 6 shows the brain serotonin levels. The result of brain serotonin level revealed no statistically significant difference $(p>0.05)$ between the treatment groups and the normal saline group.

\subsubsection{Effects of alpha-lipoic acid administration on brain-derived neurotrophic factor level in mice subjected to open-space forced swim test}

As shown in Figure 7, fluoxetine $(20 \mathrm{mg} / \mathrm{kg})$ significantly $(p<0.05)$ increased the BDNF level compared to the normal saline group. However, groups treated with ALA did not significantly $(p>0.05)$ affect the BDNF levels of the OSFST-depressed mice (Figure 7).

\subsubsection{Effects of alpha-lipoic acid administration on} serum superoxide dismutase, catalase and malondialdehyde activities in mice subjected to openspace forced swim test

As shown in Table 2, the result of superoxide dismutase (SOD), catalase and malondialdehyde (MDA) enzymes activities of the OSFST-depressed mice revealed no statistically significant difference $(p>0.05)$ between the treatment groups and the normal saline group (Table 2). 
Table 1: Effect of administration of alpha-lipoic acid on time spent on the familiar and novel object in OSFSTinduced depressed mice.

\begin{tabular}{lcc}
\hline Groups & $\begin{array}{c}\text { Time Spent on the Familiar Object } \\
\text { (seconds) }\end{array}$ & $\begin{array}{c}\text { Time Spent on the Novel Object } \\
\text { (seconds) }\end{array}$ \\
\hline Normal Saline $10 \mathrm{ml} / \mathrm{kg}$ & $1.40 \pm 0.68$ & $1.00 \pm 0.63$ \\
ALA $100 \mathrm{mg} / \mathrm{kg}$ & $1.14 \pm 0.51$ & $8.0 \pm 1.90^{*}$ \\
ALA $200 \mathrm{mg} / \mathrm{kg}$ & $6.40 \pm 0.93$ & $8.2 \pm 2.35$ \\
ALA $400 \mathrm{mg} / \mathrm{kg}$ & $1.60 \pm 0.51$ & $8.2 \pm 2.40^{*}$ \\
Fluoxetine $20 \mathrm{mg} / \mathrm{kg}$ & $1.60 \pm 0.50$ & $6.6 \pm 3.03$ \\
\hline
\end{tabular}

Data expressed as mean $\pm \mathrm{SEM},{ }^{*}$ Statistically significant compared with the time spent on the familiar object, $p<0.05,(\mathrm{n}=5)$, ALA: Alpha-Lipoic Acid

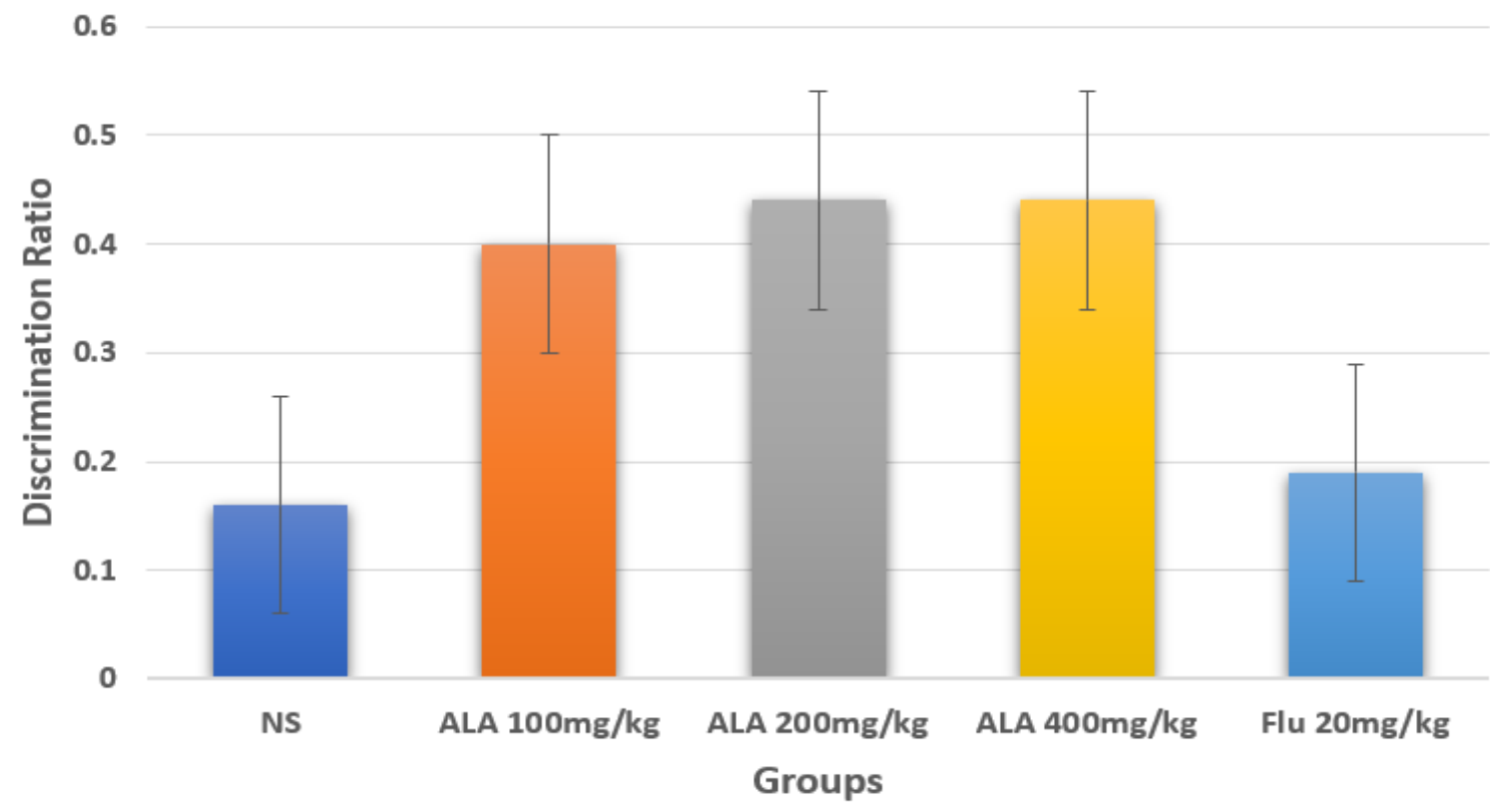

Figure 5: Novel object recognition task of OSFT-induced depressed mice. OSFT-induced depressed mice ( $n=5)$ per group were treated with graded doses of ALA (100-400 mg/kg), Flu $(20 \mathrm{mg} / \mathrm{kg})$ and NS $(10 \mathrm{ml} / \mathrm{kg})$ for 14 days, and after that, non-spatial short-term memory was assessed using NORT. ALA administration did not improve short-term memory in OFST-induced depressed mice $(p>0.05)$. Data were represented as mean \pm SEM. OSFT: Open-Space Forced Swim Test, ALA: Alpha-Lipoic Acid, Flu: Fluoxetine, NS: Normal Saline.

\subsection{DISCUSSION}

In the present work, we evaluated the effect of ALA on OSFST-induced depressed mice. We observed a significant decrease in immobility time (behavioural despair) between the ALA treated groups and the negative control (normal saline) group. Initially, the decrease in the immobility time (behavioural despair) was between ALA $(100 \mathrm{mg} / \mathrm{kg})$ and ALA $(200 \mathrm{mg} / \mathrm{kg})$ when compared with the negative control (Normal saline) group at day 7. After that, at day 10 all the ALA treatment groups and the positive control (Fluoxetine) showed a decrease in immobility time compared with negative control, with ALA $(200 \mathrm{mg} / \mathrm{kg})$ also showing a significant decrease in immobility time compared with the fluoxetine group (positive control), however, the significant effects between ALA $(200 \mathrm{mg} / \mathrm{kg})$ and fluoxetine group diminish after 14 days of treatment, although all the groups maintain a significant difference in their decreased immobility time (behavioural despair when compared with negative control. Thus, ALA decreased immobility time (behavioural despair) earlier than the standard control (fluoxetine) after just 7 days 


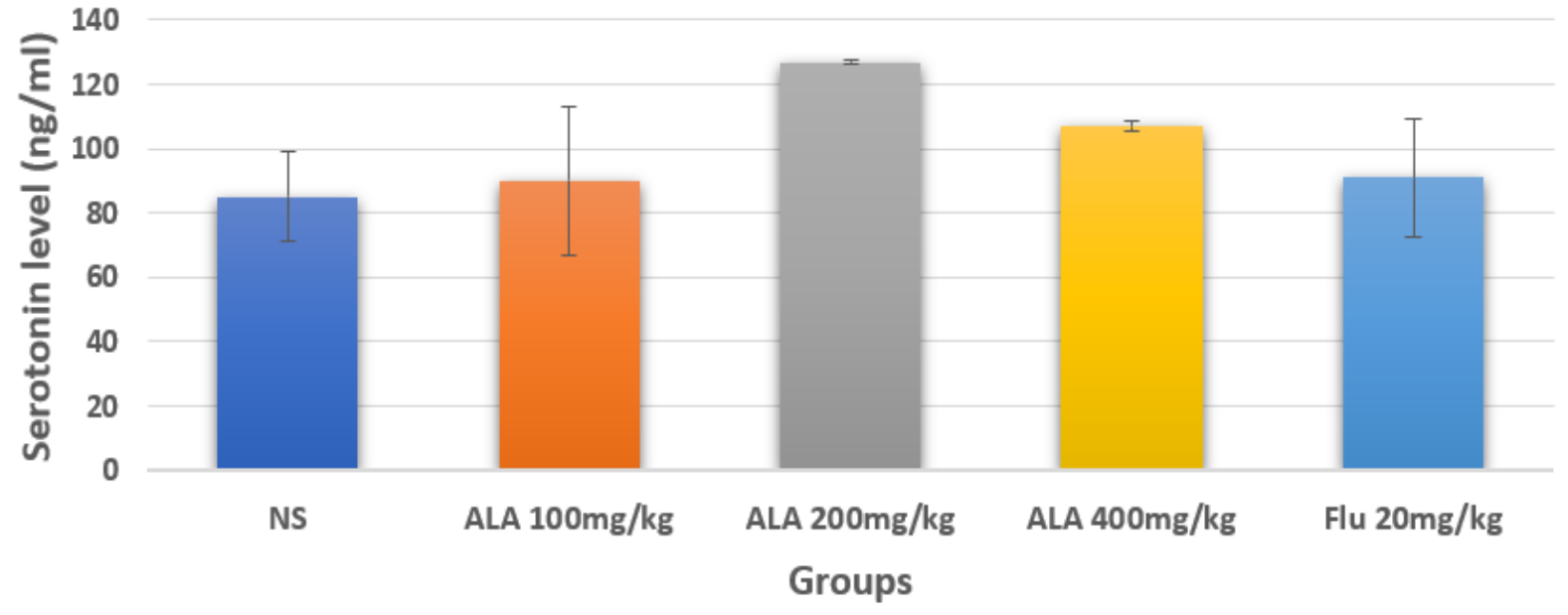

Figure 6: Brain serotonin level of OSFST-induced depressed mice. OSFST-induced depressed mice ( $\mathrm{n}=4$ ) per group were treated with graded doses of ALA (100-400 mg/kg), Flu $(20 \mathrm{mg} / \mathrm{kg})$ and NS (10 ml/kg) for 14 days and thereafter, their brain homogenates were used to assay for the serotonin using ELISA kit. ALA administration did not significantly improve the brain serotonin level of OFST-induced depressed mice $(p>0.05)$. Data were represented as mean \pm SEM. OSFST: Open-Space Forced Swim Test, ALA: Alpha-Lipoic Acid, Flu: Fluoxetine, NS: Normal Saline

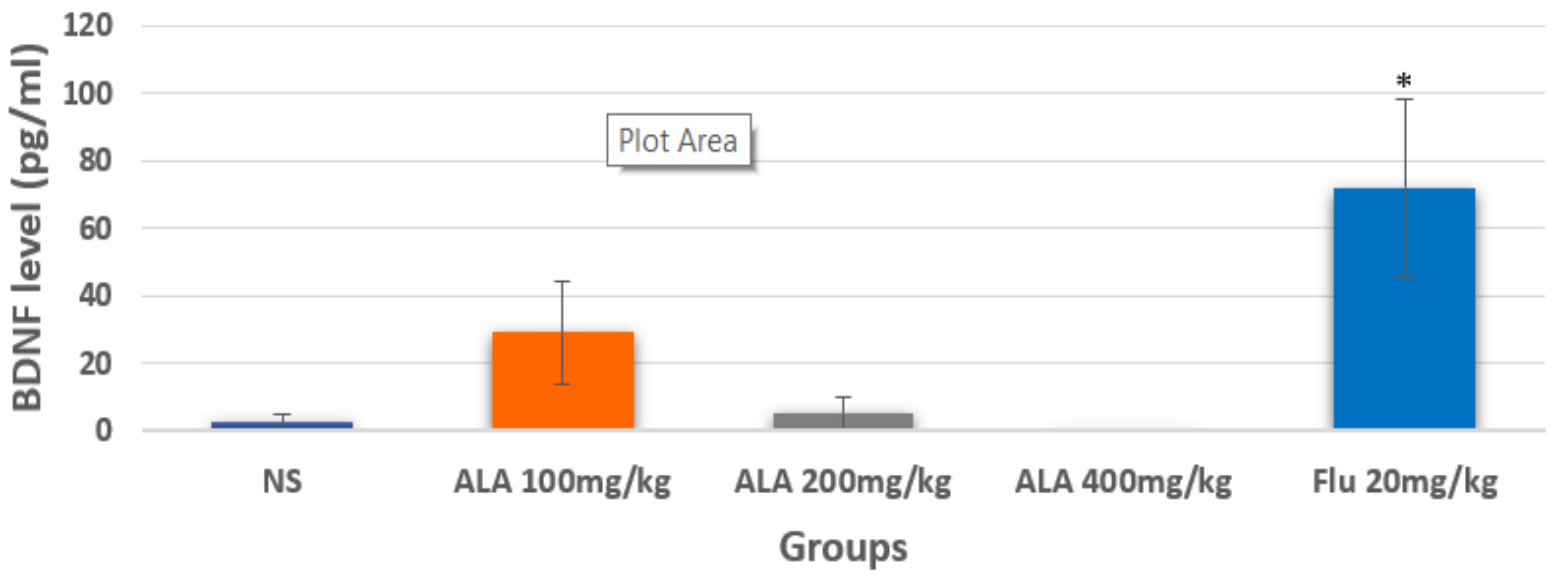

Figure 7: BDNF level of OSFST-induced depressed mice. OSFST-induced depressed mice $(\mathrm{n}=4)$ per group were treated with graded doses of ALA (100-400 mg/kg), Flu $(20 \mathrm{mg} / \mathrm{kg})$ and NS $(10 \mathrm{ml} / \mathrm{kg})$ for 14 days and thereafter, their brain homogenates were used to assay for BDNF using ELISA kit. ALA administration did not significantly improve the BDNF level of OFST-induced depressed mice $(p>0.05)$. Treatment with Flu improves BDNF level of the OSFST-induced depressed mice $(p<0.05)$. Data was represented as mean \pm SEM, *statistically significant compared with the normal saline group at $p<0.05$. OSFST: Open-Space Forced Swim Test, ALA: Alpha-Lipoic Acid, Flu: Fluoxetine, NS: Normal Saline, BDNF: Brain-Derived Neurotrophic Factor. 
Table 2: Effects of Alpha-Lipoic Acid on Oxidative Stress Biomarkers in Mice Subjected to Open-Space Forced Swim Test

\begin{tabular}{lccc}
\hline Groups & $\begin{array}{c}\text { SOD } \\
(\mathbf{U} / \mathrm{ml})\end{array}$ & $\begin{array}{c}\text { CATALASE } \\
(\mathbf{U} / \mathrm{ml})\end{array}$ & $\begin{array}{c}\text { MDA } \\
(\mathbf{p g} / \mathrm{ml})\end{array}$ \\
\hline NS $(10 \mathrm{ml} / \mathrm{kg})$ & $5.0 \pm 5.0$ & $14.0 \pm 0.7$ & $2.0 \pm 0.7$ \\
ALA $100 \mathrm{mg} / \mathrm{kg}$ & $16.3 \pm 10.0$ & $16.3 \pm 0.3$ & $3.2 \pm 1.6$ \\
ALA $200 \mathrm{mg} / \mathrm{kg}$ & $15.8 \pm 9.6$ & $20.0 \pm 5.1$ & $1.3 \pm 0.5$ \\
ALA $400 \mathrm{mg} / \mathrm{kg}$ & $11.0 \pm 6.4$ & $17.0 \pm 1.3$ & $3.7 \pm 1.0$ \\
Fluoxetine $20 \mathrm{mg} / \mathrm{kg}$ & $9.0 \pm 5.3$ & $15.5 \pm 0.5$ & $1.5 \pm 0.5$ \\
\hline
\end{tabular}

Data expressed as mean \pm SEM, $p>0.05,(n=4)$, ALA: Alpha-Lipoic Acid, SOD: Superoxide Dismutase, MDA: Malondialdehyde, NS: Normal Saline

of treatment compared with the fluoxetine group, whose effect becomes apparent after 10 days of treatment. Therefore, at the behavioural level, ALA was able to exert anti-depressant effects in depressed mice with earlier onset than standard control (fluoxetine) group and maintains its anti-depressant effects throughout the study duration (day 14). Our findings conform to Nádia et al. (2018), who reported that ALA and desvenlafaxine, alone or in combination, reversed corticosterone effect on tail suspension test and striatum. This indicates that ALA can be a promising agent for the treatment of depression and reversal of cognitive impairment observed in this disorder by reversing CORT-induced memory and social deficits.

Similarly, Oliveiraa et al. (2017) found that treatment with mirtazapine (MIRT) or MIRT+ALA for seven days effectively reverses anxiety- and depressive-like behaviours induced by CORT probably via their central antioxidant effects. In addition, Vallianou et al. (2009) reported that ALA can increase glutathione, which might help decrease depression via redox-dependent mechanisms of various cellular targets that reduce oxidative stress.

In addition, Akbari et al. (2018), in a systematic review and meta-analysis of 18 trials, reported that ALA significantly decreased C-reactive protein, tumour necrosis factor-alpha (TNF- $\alpha$ ) as well as interleukin 6 (IL6 ) in people with metabolic syndrome. These reports increase hope that ALA might possess an antidepressant effect based on the cytokine theory of depression. Furthermore, based on the monoamine hypothesis of depression, Mônica et al. (2010) found that ALA at the dose of $20 \mathrm{mg} / \mathrm{kg}$ increased norepinephrine and dopamine levels in rat hippocampus, indicating the potential of ALA to be used as an anti-depressant. However, at higher doses of 600$1800 \mathrm{mg} / \mathrm{kg}$ and in combination with acetyl-L-carnitine in depressed bipolar human patients, ALA did not show a significant anti-depressant effect (Brennan et al., 2013).

The possible mechanism via which ALA exerts its antidepressant-like effect from this present study might be to reduce behavioural despair as evidenced by decreased immobility time and promote cognitive behaviours. The possibility of involvement of the serotonergic pathway, as hypothesized by (Salazar, 2000) need to be further evaluated. However, it is important to note our limitations in this study, especially the small sample size and might limit the statistical power and duration of the study.

The results of the discrimination ratio of NORT of this study revealed that ALA did not significantly affect the non-visuospatial short-memory of mice exposed to OSFST. However, ALA showed a promising effect on the short-term memory of the mice by increasing the time spent exploring the novel object. Similarly, Farr et al. (2012) found that mice who had been given ALA before the NORT spent more time exploring the new object than mice who had not been given the drug. Previously, Nádia et al. (2018) found that ALA $200 \mathrm{mg} / \mathrm{kg}$ reversed the deficits in short-term memory in CORT-induced depressive-like behaviour and cognitive deficits using NORT. Furthermore, Saraswathy et al. (2015) found that, in a dose-dependent fashion, ALA (at doses 50, 100 and $200 \mathrm{mg} / \mathrm{kg}$ ) reversed phenytoin-induced memory impairment of rats subjected to the elevated plus-maze test. The possible mechanism might be the prevention of alterations in insulin signalling, thereby decreasing memory impairment by increasing vesicular glutamate transporter 1 (VGlut 1), which was found impaired in 
the frontal regions of HFF Alzheimer's rats with a decline in cognition (Rodriguez-perdigon et al., 2016). Another possible mechanism via which ALA improves cognition might be its central antioxidant effects (Oliveiraa et al., 2017) or restoring the central cholinergic system (Salehi et al., 2019; Zhao et al., 2015).

In the present study, we found ALA at doses of 200 and $400 \mathrm{mg} / \mathrm{kg}$ and fluoxetine $20 \mathrm{mg} / \mathrm{kg}$ showing a beneficial effect on short-term memory by increasing the spontaneous alternation ratio of the $Y$-maze test in mice exposed to the OSFST. Our findings agree with that of Nádia et al. (2018), who found that ALA $200 \mathrm{mg} / \mathrm{kg}$ reversed the deficits caused by CORT in the working memory in the Y-maze test. Similarly, treatment with ALA $\quad(50 \mathrm{mg} / \mathrm{kg}$, intraperitoneally) for 28 days significantly restored cognitive deficits induced by bilateral common carotid arteries occlusion (BCCAO) rat model of vascular dementia via restoring the central cholinergic system (Zhao et al., 2015). Furthermore, Triggiani (2020) reported that treatment with ALA inverts the increase in carbonyl protein levels in a radiation-induced cognitive dysfunction model and causes a decrease in carbonyl protein levels in elderly SAMP8 rats. Also, our findings on fluoxetine's beneficial effect on memory are in line with the study of Bortolato et al. (2016), who reported that SSRI treatment led to a significant improvement in memory performance in patients with depression. This improvement was observed in intermediate \& delayed verbal, immediate visual and declarative memory. Possibly, the mechanism via which fluoxetine enhanced spatial short-term memory of the mice from the present study might be via increased BDNF level.

Thereafter, brain serotonin \& BDNF, as well as oxidative stress biomarkers, were assayed. ALA in this study did not significantly increase the brain serotonin level of mice subjected to OSFST. However, the study by Bist \& Kumar (2009) showed that, in combination with vitamin $E, A L A$ reversed the decline in serotonin level of crude homogenate of the whole brain of mice observed in lindane-induced acute neurotoxicity. Although, in our study, the animals were induced with depression via the forced swimming method. Similarly, (Triggiani, 2020) reported in a review that treatment with ALA could improve the function of the serotonin neurotransmitter in a neurodegenerative disease model. Perhaps, our subjects in this study are young, healthy mice subjected to a depressive model, which might be the variation.
Also, the hypothesis of Salazar (2000) indicated that ALA might possess anti-depressant activity by increasing insulin sensitivity that can lead to an increase in tryptophan absorption with a subsequent increase in serotonin. Contrary to these findings, Mônica et al. (2010) found that acute administration of ALA at a low dose of $20 \mathrm{mg} / \mathrm{kg}$ decreased rat hippocampal serotonin level 24 hours after administration. Although, we administered ALA for 2 weeks and at higher doses than the ones in their study. Also, it is important to note one of our limitations in this study, using a small sample size and non-repetition of the experiment.

In our study, ALA did not significantly affect the whole brain BDNF level of mice subjected to OSFST. However, Filho et al. (2014) found that treatment with ALA 200 $\mathrm{mg} / \mathrm{kg}$ for 7 days significantly increased BDNF level in mice prefrontal cortex in corticosterone (CORT) induced depression model. Similarly, Nádia et al. (2015) reported that ALA $200 \mathrm{mg} / \mathrm{kg}$ reversed CORT-induced decrease in BDNF in the hippocampus and striatum of female mice. This indicates that ALA may serve as a valuable agent in treating depression based on the neurotrophic hypothesis of the disorder.

Fluoxetine significantly increased the BDNF level of mice exposed to OSFST in this study. This finding agrees with that of Liu et al. (2014), who found that fluoxetine significantly increased serum BDNF level with improved cognitive recovery in patients with vascular dementia. Similarly, Paula et al. (2020) reported that antidepressant treatment promotes the synthesis of BNDF and enhances neurogenesis. In addition, the use of antidepressant medication in MDD patients was found associated with increased BDNF mRNA expression in the brain (Giacobbo et al., 2018).

In this study, the results of the serum antioxidant enzymes (SOD and Catalase) showed that ALA did not significantly affect their activities in the mice subjected to OSFST. However, a study by Veskovic et al. (2014) revealed that administration of ALA at the dose of 100 $\mathrm{mg} / \mathrm{kg}$ IP caused an increase in catalase activity in cortex and striatum and GSH content in the hypothalamus. In addition, ALA treatment significantly reduced lipid peroxidation and nitrosative stress, caused by methionine and choline deficiency diet in all brain regions by restoring antioxidant enzymes activities, predominantly total SOD, manganese SOD, and copper and zinc SOD, and by modulating catalase activity and glutathione content to a lesser extent. 
It is important to note the controversy regarding the change in SOD and catalase activities in depressive patients. Interruptions in SOD activity are usually found in depressive patients, but the findings are still inconsistent (Paula et al., 2020). Reduced SOD activity has been found in MDD patients (Rybka et al., 2013). However, a rise in SOD and catalase activities in depressive patients has been reported from other studies (Kodydková et al., 2009). In addition, a study showed that serum SOD and catalase activities were significantly higher in the acute phase of MDD patients, showing possibly that increased activities of both antioxidant enzymes might be indicators of acute depressive episodes on MDD (Tsai and Huang, 2016).

We found in this study that; ALA did not significantly change the serum MDA activity of the mice subjected to OSFST. However, Manda et al. (2008) found that pretreatment with ALA exerted a very high magnitude of protection against radiation-induced augmentation of lipid peroxidation products (malondialdehyde) and protein carbonyls in mice cerebellum. Similarly, Khalifa et al. (2020) found that the MDA level was significantly lower when ALA was combined with coenzyme Q10 (CoQ10) in the cisplatin-induced nephrotoxicity murine model. Another study by Zalejska-fiolka et al. (2015) reported that dietary ALA and garlic intake was significantly associated with a decline in 6Hydroxydopamine (8OHdG) and MDA levels in rabbits' liver tissue. In addition, MDA level was observed at the lowest level in ALA $100 \mathrm{mg} / \mathrm{kg}$ treated group compared to control and noise exposure groups in a noise-induced oxidative stress rat model (Karafakioğlu, 2018). However, none of the studies above induced depression before assessing the MDA as done in this study.

\subsection{CONCLUSIONS}

Our study demonstrated that ALA exerts antidepressant-like effects on OSFST depressed mice and improves their cognition through a mechanism independent of antioxidant effect and increased serotonin and BDNF levels. Therefore, ALA is a potential anti-depressant drug that can attenuate depressive symptoms in depressed individuals. However, in this study, the effect of ALA on the cholinergic system, inflammatory markers and norepinephrine system was not evaluated. Nevertheless, further study on the efficacy of ALA in animal models of depression, cognition and anxiety are needed.

Acknowledgements: Acknowledgement goes to Institution Based Research Fund intervention of Tertiary Education Trust Fund, Nigeria (DAPM/TETFUND/01/12) for supporting this research work.

Author Contributions: JY and YY conceptualized the design of the study. AAW, MIAS, and JY supervised the study. YY prepared the first draft of the manuscript. JY and UMA improved the drafted manuscript, and UMA helped in the statistical analysis. All authors contributed and agreed to the final version of the manuscript.

Conflicts of Interest: The authors declare no conflict of interest.

\section{References}

Akbari, M., Ostadmohammadi, V., Lankarani, K. B., Tabrizi, R., Kolahdooz, F., Khatibi, S. R., \& Asemi, Z. (2018). The effects of alpha-lipoic acid supplementation on glucose control and lipid profiles among patients with metabolic diseases: $\mathrm{A}$ systematic review and meta-analysis of randomized controlled trials. Metabolism, 87, 56-69. https://doi.org/10.1016/i.metabol.2018.07.002

Baldessarini, R. J., Vázquez, G. H., \& Tondo, L. (2020). Bipolar depression : a major unsolved challenge. International Journal of Bipolar Disorders, 8, 1-13. https://doi.org/10.1186/s40345-019-0160-1

Bist, R., \& Kumar, D. (2009). The evaluation of effect of alpha-lipoic acid and vitamin $E$ on the lipid peroxidation , gammaamino butyric acid and serotonin level in the brain of mice (Mus musculus) acutely intoxicated with lindane. Journal of the Neurological Sciences, 276(2009), 99-102. https://doi.org/10.1016/i.jns.2008.09.008

Bortolato, B., Miskowiak, K. W., Köhler, C. A., Maes, M., Fernandes, B. S., Berk, M., \& Carvalho, A. F. (2016). Cognitive remission: a novel objective for the treatment of major depression ? BMC Medicine, 14(9), 1-18. https://doi.org/10.1186/s12916-016-0560-3

Brennan, B. P., John, P., Jensen, E., Hudson, D. J. I., Coit, C. E., Beaulieu, A., Pope, H. G., Renshaw, P. F., \& Cohen, B. M. (2013). A placebo-controlled trial of acetyl-L-carnitine and $\alpha$-lipoic acid in the treatment of bipolar depression. Journal of Clinical Psychopharmacology, 33(5), 627-635. https://doi.org/10.1097/JCP.0b013e31829a83f5

Brown, J. M., Stewart, J. C., Stump, T. E., \& Callahan, C. M. (2011). Risk of coronary heart disease events over 15 years among older adults with depressive symptoms. American Journal of Geriatric Psychiatry, 19(8), 721-729.

https://doi.org/10.1097/JGP.0b013e3181faee19 
Calheiros, M., Silva, C., Nádia, C., \& Sousa, S. De. (2013). Augmentation therapy with alpha-lipoic acid and desvenlafaxine: A future target for treatment of depression? Naunyn-Schmiedeberg's Archives of Pharmacology, 386, 685-695. https://doi.org/10.1007/s00210-013-0867-y

Çekici, H., \& Bakırhan, Y. E. (2018). Potential therapeutic agent in psychiatric and neurological diseases: alpha lipoic acid. Acta Psychopathologica, 4(2), 1-6. https://doi.org/10.4172/2469-6676.100165

Choi, K., Park, M., Kim, H., Kim, K., Kim, H., Kim, J., Kim, B., Kim, M., Park, J., \& Cho, K. (2015). Alpha-lipoic acid treatment is neurorestorative and promotes functional recovery after stroke in rats. Molecular Brain, 8(9), 1-16. https://doi.org/10.1186/s13041-015-0101-6

Darcet, F., Gardier, A. M., Gaillard, R., David, D. J., \& Guilloux, J. P. (2016). Cognitive dysfunction in major depressive disorder. A translational review in animal models of the disease. Pharmaceuticals, 9(1), 1-42. https://doi.org/10.3390/ph9010009

DeSousa, S. C. N., Meneses, N. L., Vasconcelos, S. G., daSilva, Márcia Calheiros Macêdo, D., DeLucena, D. F., \& Vasconcelos, S. M. M. (2015). Reversal of corticosterone-induced BDNF alterations by the natural antioxidant alpha-lipoic acid alone and combined with desvenlafaxine : Emphasis on the neurotrophic hypothesis of depression. Psychiatry Research, 2015, 1-9. https://doi.org/10.1016/i.psychres.2015.08.042

Dong, K., Hao, P., Xu, S., Liu, S., Zhou, W., Yue, X., Rausch-FAN, X., \& Liu, Z. (2017). Alpha-lipoic acid alleviates high-glucose Ssuppressed osteogenic differentiation of MC3T3-E1 cells via antioxidant effect and PI3K / Akt signaling pathway. Cellular Physiology and Biochemistry, 42, 1897-1906. https://doi.org/10.1159/000479605

Farr, S. A., Price, T. O., Banks, W. A., Ercal, N., Morley, J. E., Medicine, G., Louis, S., Louis, S., Louis, S., \& Louis, S. (2012). Effect of alpha-lipoic acid on memory , oxidation , and lifespan in SAMP8 mice. Journal of Alzheimer's Disease, 32(2012), 447455. https://doi.org/10.3233/JAD-2012-120130

Filho, M. H. N. R., Sousa, C. N. S. De, Meneses, L. N., Vasconcelos, G. S., Silva, M. C. C., Patrocínio, M. C. A., Filho, L. C. O., Oliveira, T. Q., Júnior, M. A. S., \& Vasconcelos, S. M. M. (2014). Antidepressant effect of alpha-lipoic acid : Brain-derived Neurotrophic Factor such as a new target for resistant depression. European Neuropsychopharmacology, 24(Suppl 2), 81-82. https://doi.org/10.1016/S0924-977X(14)70393-1

Giacobbo, B. L., Doorduin, J., Klein, H. C., Dierckx, R. A. J. O., Bromberg, E., \& Vries, E. F. J. De. (2018). Brain-derived neurotrophicfactor in brain disorders: focus on neuroinflammation. Molecular Neurobiology, 2018, 1-18. https://doi.org/10.1007/s12035-018-1283-6

Habila, N., H.M. Inuwa, Aimola, I. A., Lasisi, O. I., Muhammad, A., A., I. O., \& Williams, I. S. (2012). Acetylcholinesterase activity in the brain and blood of mice infected with Naja nigricolis venom. Biological Segment, 3(1), 5-14.

Hashimoto, K. (2019). Rapid-acting anti-depressant ketamine, its metabolites and other candidates: A historical overview and future perspective. Psychiatry and Clinical Neurosciences, 73, 613-627. https://doi.org/10.1111/pcn.12902

Karaarslan, U., İşgüder, R., Bağ, Ö., Kışla, M., \& Ağın, H. (2013). Alpha lipoic acid intoxication , treatment and outcome. Clinical Toxicology, 51(6), 522-522. https://doi.org/10.3109/15563650.2013.801983

Karafakioğlu, Y. S. (2018). Effects of $\alpha$ lipoic acid on noise induced oxidative stress in rats. Saudi Journal of Biological Sciences, 2018(August), 1-21. https://doi.org/10.1016/i.sjbs.2018.08.008

Katerji, M., Filippova, M., \& Duerksen-hughes, P. (2019). Approaches and methods to measure oxidative stress in clinical samples : research applications in the cancer field. Oxidative Medicine and Cellular Longevity, 2019, 1-29. https://doi.org/10.1155/2019/1279250

Khalifa, E. A., Ahmed, A. N., Hashem, K. S., \& Allah, A. G. (2020). Therapeutic effects of the combination of alpha-lipoic acid ( ALA ) and coenzyme Q10 ( CoQ10 ) on cisplatin-induced nephrotoxicity. International Journal of Inflammation, 2020, 111. https://doi.org/10.1155/2020/5369797

Kodydková, J., Vávrová, L., Zeman, M., Jirák, R., Macá, J., Sta, B., \& Tvrzická, E. (2009). Antioxidative enzymes and increased oxidative stress in depressive women. Clinical Biochemistry, 42(2009), 1368-1374. https://doi.org/10.1016/i.clinbiochem.2009.06.006

Kurumazuka, D., Kitada, K., Tanaka, R., Mori, T., Ohkita, M., Takaoka, M., \& Matsumura, Y. (2019). $\alpha$-Lipoic acid exerts a primary prevention for the cardiac dysfunction in aortocaval fistula-created rat hearts. Heliyon, 5(2019), e02371. https://doi.org/10.1016/i.heliyon.2019.e02371

Liu, B., Liu, J., Wang, M., Zhang, Y., \& Li, L. (2017a). From serotonin to neuroplasticity: Evolvement of theories for major depressive disorder. Frontiers in Cellular Neuroscience, 11(September), 1-9. https://doi.org/10.3389/fncel.2017.00305

Liu, X., Zhang, J., Sun, D., Fan, Y., Zhou, H., \& Fu, B. (2014). Effects of fluoxetine on brain-derived neurotrophic factor serum concentration and cognition in patients with vascular dementia. Clinical Interventions in Aging, 2014(9), 411-419. https://doi.org/10.2147/CIA.S58830

Liu, Z., Patil, I., Sancheti, H., Yin, F., \& Cadenas, E. (2017b). Effects of lipoic acid on high-fat diet-induced alteration of synaptic plasticity and brain glucose metabolism : A PET / CT and 13 C-NMR study. Scientific Reports, December 2016, 1-13. https://doi.org/10.1038/s41598-017-05217-z

Manda, K., Ueno, M., \& Anzai, K. (2008). Memory impairment, oxidative damage and apoptosis induced by space radiation: Ameliorative potential of alpha lipoic acid. Behavioural Brain Research, 187(2008), 387-395. 
https://doi.org/10.1016/i.bbr.2007.09.033

Marcia, C. C. S., Caren-Nadia, S. S., Patrícia, X. L. G., Gersilene, V. O., Fernanda, Y. R. A., Naiara, C. X., Jéssica, C. S., German, S. V., Luzia, K. A. M. L., Danielle, M., \& Silvania, M. M. V. (2016). Evidence for protective effect of lipoic acid and desvenlafaxine on oxidative stress in a model depression in mice. Progress in Neuro-Psychopharmacology Biological Psychiatry, 64, 142-148. https://doi.org/10.1016/j.pnpbp.2015.08.002

Mendoza-núñez, V. M., García-martínez, B. I., Rosado-pérez, J., Santiago-osorio, E., \& Pedraza-chaverri, J. (2019). The effect of $600 \mathrm{mg}$ alpha-lipoic acid supplementation on oxidative stress, inflammation, and RAGE in older adults with Type 2 diabetes mellitus. Oxidative Medicine and Cellular Longevity, 2019, 1-12. https://doi.org/10.1155/2019/3276958

Mônica, Í., Santos, D. S., Lyne, R., \& Freitas, M. De. (2010). Alterations on monoamines concentration in rat hippocampus produced by lipoic acid. Arq Neuropsiquiatr, 68(3), 362-366. https://doi.org/10.1590/s0004-282x2010000300006

Nádia, C., Sousa, S. De, Meneses, L. N., Vasconcelos, G. S., Medeiros, S., Calheiros, M., Silva, C., Mouaffak, F., Kebir, O., Manuel, C., Leite, S., Cláudio, M., Patrocinio, A., Macedo, D., Maria, S., \& Vasconcelos, M. (2018). Neuroprotective evidence of alpha-lipoic acid and desvenlafaxine on memory deficit in a neuroendocrine model of depression. NaunynSchmiedeberg's Archives of Pharmacology, 2018, 1-15. https://doi.org/10.1007/s00210-018-1509-1

Okanović, A., Prnjavorac, B., Jusufović, E., \& Sejdinović, R. (2015). Alpha-lipoic acid reduces body weight and regulates triglycerides in obese patients with diabetes mellitus. Medicinski Glasnik, 12(2), 96-101. https://doi.org/10.17392/798$\underline{15}$

Oliveiraa, T. de Q., DeSousaa, C. N. S., Vasconcelosa, G. S., DeSousaa, L. C., DeOliveiraa, A. A., Patrocíniob, C. F. V., Medeiros, I. da S., Júnior, J. E. R. H., Maes, M., Macedo, D., \& Vasconcelos, S. M. M. (2017). Brain antioxidant effect of mirtazapine and reversal of sedation by its combination with alpha-lipoic acid in a model of depression induced by corticosterone. Journal of Affective Disorders, 05(22), 1-31. https://doi.org/10.1016/i.jad.2017.05.022

Paula, A., Visentin, V., Colombo, R., Scotton, E., Fracasso, D. S., Ribeiro, A., Branco, C. S., \& Salvador, M. (2020). Targeting inflammatory-mitochondrial response in major depression: current evidence and further challenges. Oxidative Medicine and Cellular Longevity, 2020, 1-20. https://doi.org/10.1155/2020/2972968

Rodriguez-perdigon, M., Solas, M., Moreno-aliaga, M. J., \& Javier, M. (2016). Lipoic acid improves neuronal insulin signalling and rescues cognitive function regulating VGlut1 expression in high-fat-fed rats : Implications for Alzheimer's disease. BBA - Molecular Basis of Disease, 1862(4), 511-517. https://doi.org/10.1016/i.bbadis.2016.01.004

Rybka, J., Kornelia, K., Bana, P., Majsterek, I., Carvalho, L. A., Cattaneo, A., \& Anacker, C. (2013). Interplay between the prooxidant and antioxidant systems and proin $\mathrm{fl}$ ammatory cytokine levels, in relation to iron metabolism and the erythron in depression. Free Radical Biology and Medicine, 63, 187-194. https://doi.org/10.1016/i.freeradbiomed.2013.05.019

Salazar, M. R. (2000). Alpha lipoic acid : a novel treatment for depression. Medical Hypotheses, 55(6), 510-512. https://doi.org/10.1054/mehy.2000.1103

Salehi, B., Yılmaz, Y. B., Antika, G., Tumer, T. B., Mahomoodally, M. F., Lobine, D., Akram, M., Riaz, M., Capanoglu, E., \& Sharopov, F. (2019). Insights on the use of $\alpha$-lipoic acid for therapeutic purposes. Biomolecules, 9(356), 1-25. https://doi.org/10.3390/biom9080356

Saraswathy, G., Maheswari, E., \& Santhrani, T. (2015). Protective effect of alpha lipoic acid against phenytoin induced behavioral abnormalities in rats. Journal of Molecular Biomarkers \& Diagnosis, 6(4), 1-10. https://doi.org/10.4172/21559929.1000241

Schweizer, S., Kievit, R. A., Emery, T., \& Henson, R. N. (2018). Symptoms of depression in a large healthy population cohort are related to subjective memory complaints and memory performance in negative contexts. Psychological Medicine, 48(1), 104-114. https://doi.org/10.1017/S0033291717001519

Serafini, G. (2012). Neuroplasticity and major depression, the role of modern anti-depressant drugs. World Journal of Psychiatry, 2(3), 49-57. https://doi.org/10.5498/wip.v2.i3.49

Silva, G., Coelho, N., Nádia, C., Sousa, S. De, Queiroz, T. De, Ladislau, L., Lima, L., Freitas, D., Lucena, D., Severino, C., Macêdo, D., Maria, S., \& Vasconcelos, M. (2015). Alpha-lipoic acid alone and combined with clozapine reverses schizophrenia-like symptoms induced by ketamine in mice: Participation of antioxidant, nitrergic and neurotrophic mechanisms. Schizophrenia Research, 2015, 1-8. https://doi.org/10.1016/i.schres.2015.04.017

Spielman, L. J., Little, J. P., \& Klegeris, A. (2014). Inflammation and insulin / IGF-1 resistance as the possible link between obesity and neurodegeneration. Journal of Neuroimmunology, 273(2014), 8-21. https://doi.org/10.1016/i.jneuroim.2014.06.004

Stone, E. A., \& Lin, Y. (2011). Open-space forced swim model of depression for mice. Curr Protoc Neurosci., 5740, 1-12. https://doi.org/10.1002/0471142301.ns0936s54.Open-Space

Stuart, M. J., \& Baune, B. T. (2012). Depression and type 2 diabetes : inflammatory mechanisms of a psychoneuroendocrine co-morbidity. Neuroscience and Biobehavioral Reviews, 36(1), 658-676. https://doi.org/10.1016/j.neubiorev.2011.10.001

Thur, K. E., Nelson, A. J. D., \& Cassaday, H. J. (2014). Ro 04-6790-induced cognitive enhancement : No effect in trace conditioning and novel object recognition procedures in adult male Wistar rats. Pharmacology, Biochemistry and 
Behavior, 127, 42-48. https://doi.org/10.1016/i.pbb.2014.10.006

Tsai, M., \& Huang, T. (2016). Increased activities of both superoxide dismutase and catalase were indicators of acute depressive episodes in patients with major depressive disorder. Psychiatry Research, 30; 235, 38-42.

https://doi.org/10.1016/i.psychres.2015.12.005

Triggiani, L. (2020). Potential therapeutic effects of alpha lipoic acid in memory disorders. Progress in Nutrition, 22(1), 12-19. https://doi.org/10.23751/pn.v22i1.9341

Uchida, R., Okamoto, H., Ikuta, N., Terao, K., \& Hirota, T. (2015). Enantioselective pharmacokinetics of $\alpha$-lipoic acid in rats. International Journal of Molecular Sciences, 16, 22781-22794. https://doi.org/10.3390/ijms160922781

Vallianou, N., Evangelopoulos, A., \& Koutalas, P. (2009). Alpha-lipoic acid and diabetic neuropathy. The Review of Diabetic Studies, 6(4), 230-236. https://doi.org/10.1900/RDS.2009.6.230

Veskovic, M., Mladenovic, D., Jorgacevic, B., Stevanovic, I., \& Luka, S. De. (2014). Alpha-lipoic acid affects the oxidative stress in various brain structures in mice with methionine and choline deficiency. Experimental Biology and Medicine 2014; 0 , 1-8. https://doi.org/10.1177/1535370214549521

Volchegorskiĭ, I. A., Rassokhina, L. M., Koliadich, M. I., \& Alekseev, M. I. (2011). Comparative study of alpha-lipoic acid and mexidol effects on affective status, cognitive functions and quality of life in diabetes mellitus patients]. Eksperimental'naia i Klinicheskaia Farmakologiia, 74(11), 17-23. http://europepmc.org/abstract/MED/22288155

WHO. (2017). Depression and other common mental disorders: global health estimates. World Health Organization. https://apps.who.int/iris/bitstream/10665/254610/1/WHO_MSD_MER_2017.2

WHO. (2021). Key facts - Depression. World Health Organization. https://www.who.int/news-room/factsheets/detail/depression?

Wolf, A., Bauer, B., Abner, E. L., Ashkenazy-frolinger, T., \& Anika, M. (2016). A Comprehensive Behavioral Test Battery to Assess Learning and Memory in 129S6 / Tg2576 Mice. PLOS ONE, 11(1), 1-23. https://doi.org/10.1371/journal.pone.0147733

Wroolie, T. E., Williams, K. E., Keller, J., Zappert, L. N., Shelton, S. D., Kenna, H. A., Reynolds, M. F., \& Rasgon, N. L. (2006). Mood and neuropsychological changes in women with midlife depression treated with escitalopram. Journal of Clinical Psychopharmacology, 26(4), 361-366. https://doi.org/10.1097/01.jcp.0000227699.26375.f8

Yau, J. L. W., Mcnair, K. M., Noble, J., Brownstein, D., Hibberd, C., Morton, N., Mullins, J. J., Morris, R. G. M., Cobb, S., \& Seckl, J. R. (2007). Enhanced hippocampal long-term potentiation and spatial learning in aged 11 B-hydroxysteroid dehydrogenase Type 1 knock-out mice. The Journal of Neuroscience, 27(39), 10487-10496. https://doi.org/10.1523/JNEUROSCl.2190-07.2007

Zalejska-fiolka, J., N, T. W., Jr, W. R., Natalia, D., Strzelczyk, J. K., Kasperczyk, A., Owczarek, A., Urszula, B. B., Kasperczyk, S. B., Stawiarska-pi, B., Birkner, E., \& Gamian, A. (2015). The influence of $\alpha$-lipoic acid and garlic administration on biomarkers of oxidative stress and inflammation in rabbits exposed to oxidized nutrition oils. BioMed Research International, 2015, 1-11. https://doi.org/10.1155/2015/827879

Zatta, P., Zambenedetti, P., Kilyen, M., \& Kiss, T. (2002). In vivo and in vitro effects of aluminium on the activity of mouse brain acetylcholinesterase. Brain Research Bulletin, 59(1), 41-45. https://doi.org/10.1016/s0361-9230(02)00836-5

Zemdegs, J., Rainer, Q., Grossmann, C. P., Rousseau-ralliard, D., Grynberg, A., Ribeiro, E., \& Guiard, B. P. (2018). Anxiolyticand antidepressant-like effects of fish oil-enriched diet in brain-derived neurotrophic factor deficient mice. Frontiers in Neuroscience, 12, 1-16. https://doi.org/10.3389/fnins.2018.00974

Zhao, R., Xu, F., Xu, X., Tan, G., Liu, L., Wu, N., Zhang, W., \& Liu, J. (2015). Effects of alpha-lipoic acid on spatial learning and memory, oxidative stress, and central cholinergic system in a rat model of vascular dementia. Neuroscience Letters, 587, 113-119. https://doi.org/10.1016/i.neulet.2014.12.037 